\section{Responsabilidad médica: el dilema entre la Justicia civil y la penal}

\section{Medical liability: the dilemma between civil and criminal justice}

\section{Sr. Editor:}

El establecimiento de la Reforma de Salud el año 2005 conllevó, entre otros aspectos, la implementación de un procedimiento prejudicial denominado mediación, para todos los casos en que los pacientes sintieran vulnerados sus derechos y quisieran acudir a la justicia civil. En estas circunstancias la mediación corresponde a un procedimiento obligatorio, ejecutado por el Consejo de Defensa del Estado (CDE) para los casos generados en mundo público y por la Superintendencia de Salud (SIS) en los casos privados. A la fecha, se ha descrito como un importante resultado de la mediación el efecto desincentivador que esta provoca, es decir, aún en aquellos casos que no se logra acuerdo durante la mediación misma, sólo $10,7 \%$ de los casos públicos continúa en un juicio ${ }^{1}$. Bajo esa perspectiva, pareciera que la mediación es efectiva en desalentar la excesiva judicialización de la medicina.

Atendido lo anterior, en el mes de agosto recién pasado el Ministerio Público y el CDE firmaron un convenio con el objetivo de "promover una eficiente, rápida y coordinada entrega de información a víctimas de cuasidelitos cometidos con ocasión de una atención de salud en centros asistenciales públicos", es decir, en términos simples, promueven entre los usuarios que buscan ser resarcidos a través del sistema penal -donde la mediación no es obligatoria- los beneficios que poseen la mediación existente en la justicia civil, y que opten por esta última.

Aquí subyace un hecho concreto y dos preguntas. Lo concreto, es que la mediación es obligatoria en salud sólo para las causas civiles y no para las penales. Y hay un mundo de diferencia en ello.

Respecto a las preguntas, la primera tiene que ver con la casuística: ¿Es tan relevante el número de casos de responsabilidad médica (responsabilidad sanitaria mejor dicho, porque involucra mucho más que solo a los médicos) en el sistema penal, que logra que el CDE y las Fiscalías articulen un procedimiento que permitan transitar entre la justicia penal y la civil de forma más amable? Y segundo, ¿cómo los usuarios de la salud disconformes toman la decisión de acudir a la justicia civil o a la penal?

La respuesta a la primera pregunta demuestra la complejidad del tema: somos capaces de determinar y clasificar el número de nuevos casos de mediación que ingresan anualmente al CDE y a la SIS, pero no conocemos al detalle cuántos nuevos casos ingresan a la justicia penal. Además, contra el vaticinio que efectuara Pizarro ${ }^{2}$, todo indica que la Reforma Procesal Penal no provocó un aumento de las causas civiles de responsabilidad sanitaria en desmedro de las penales.

La respuesta a la segunda pregunta es más compleja aún y puede ser contestada con otra pregunta. ¿Qué factores existen para que los usuarios opten por presentar sus casos de responsabilidad sanitaria ante la justicia penal, atochando las Fiscalías, criminalizando a los profesionales afectados, exponiéndose a tramitaciones extensísimas y escasas posibilidades de compensaciones económicas?. ¿Son sólo los factores de alfabetización del sistema judicial lo que conduce a los pacientes a optar por la justicia penal antes que la civil?. No lo sabemos, y difícilmente podemos aclarar estas dudas porque carecemos de información estadística precisa ${ }^{3}$. Esta divergencia penal -civil se acrecienta aún más cuando profundizamos en el abordaje que tienen los casos de responsabilidad sanitaria según su origen, tal como lo menciona Carlos Pizarro3. "Este doble tratamiento de la responsabilidad médica no se justifica. El derecho debería responder con las mismas reglas, ya sea que el acto médico tenga lugar en un hospital público o privado."

En vista a lo anterior, tal vez sea hora de repensar el tratamiento jurídico que damos a la responsabilidad sanitaria. Ya lo menciona Roberto Sotomayor, el 30 de enero de este año en La Tercera, en una carta en la que propone una judicatura especial para atender a las personas insatisfechas con la atención en salud ${ }^{4}$, pues todo indica que es tiempo de propiciar un modelo que, siendo justo y oportuno, evite la criminalización de los profesionales y de respuesta a los requerimientos de los pacientes, pues, tal como consigan múltiples autores, la mayoría de las veces sólo quieren una explicación y/o disculpas ${ }^{5,6}$.

\section{Karla Moscoso-Matus ${ }^{1}$ \\ ${ }^{1}$ Odontólogo Legista, Unidad Auditoría Interna, Servicio Médico Legal, Santiago de Chile}

\section{Referencias}

1. Lagos S. Impacto de la mediación en la judicialización de conflictos jurídicamente relevantes: un análisis a base de la experiencia chilena de medición por daños en la salud. Revista de Estudios de la Justicia. doi:10.5354/07184735.2013.29919.

2. Pizarro C. Responsabilidad profesional médica: Diagnóstico y perspectivas. Rev Med Chile 2008; 136: 539-43.

3. Moscoso K, Smok P. Responsabilidad sanitaria en odontólogos. Casuística de casos evaluados en el Servicio Médico Legal de Chile. Rev Med Chile 2015; 143: 345-51.

4. Carta al editor http://diario.latercera.com/2016/01/30/01/ contenido/opinion/11-208283-9-reclamos-por-la-atencionen-salud.shtml [visitado el 30 de enero de 2016]. 
5. Sohn D, Bal S. Medical Malpractice Reform: The Role of Alternative Dispute Resolution. Clinical Orthopaedics and Related Research 2012; 470: 1370-8. Disponible: www.ncbi. nlm.nih.gov/pmc/articles/PMC3314770/ [visitado el 7 de enero de 2015]

6. Elango S. Medical Negligence Suits: Risk Management. The Medical Journal of Malaysia 2003; 58 (4): 625-31.
Fuentes de apoyo financiero: no hubo.

Correspondencia a:

Dra. Karla Moscoso Matus

Teatinos \#240, Santiago, teléfono 2-28929200

kmoscoso@gmail.com 